\title{
Violência sexual contra crianças na mídia impressa: gênero e geração*
}

\author{
Tatiana Savoia Landini**
}

\begin{abstract}
Resumo
O presente trabalho objetiva resgatar o que foi publicado sobre violência sexual contra crianças e adolescentes por um jornal de grande circulação, $O$ Estado de S.Paulo. A pesquisa abrangeu o século XX e cobre as diversas formas de violência sexual: incesto, crimes violentos cometidos por estranhos, crimes contra a honra, lenocínio e prostituição, pornografia infantil e pedofilia. Apresento o material em dois blocos: o primeiro reporta ao início do século e o segundo ao final do período, procurando chamar a atenção para a forma como os crimes sexuais eram noticiados e para os sentimentos sociais presentes nesses textos. $\mathrm{Na}$ conclusão, analiso as principais transformações na forma do jornal noticiar a violência sexual.
\end{abstract}

Palavras-chave: Violência Sexual, Violência contra a Criança, Sexualidade, Gênero, Mídia.

\footnotetext{
" Recebido para publicação em janeiro de 2006, aprovado em abril de 2006. O presente artigo foi escrito a partir de minha tese de doutorado - Honra, horror e direitos - violência sexual contra crianças e adolescentes no século XX defendida em 2005 junto ao Departamento de Sociologia da FFLCH/USP. À minha orientadora, Maria Helena Oliva Augusto, devo um agradecimento especial por todo o apoio e incentivo durante a pesquisa e redação da tese. Seus questionamentos e sugestões foram essenciais para o trabalho.

** Doutora pelo Departamento de Sociologia da FFLCH/USP.

tatalan@uol.com.br
}

cadernos pagu (26), janeiro-junho de 2006: pp.225-252. 
Violência sexual contra crianças na mídia impressa

Sexual Violence Against Children in the Press:

Gender and Generation

\begin{abstract}
The aim of this paper is to show what has been published on child sexual violence by $O$ Estado de S.Paulo, a well-sold Brazilian daily newspaper. The research covered the $20^{\text {th }}$ century and the many forms of sexual violence: incest, crimes committed by strangers, honour crimes, prostitution, child pornography and paedophilia. The data will be presented in two parts: the first one covering the beginning of the century and the second one the last decades. On doing this, I focus on how sexual crimes were reported and, also, on the social sensibility that can be drawn from the news. The main changes on how the newspaper talks about sexual violence are analyzed in the conclusion.
\end{abstract}

Key Words: Sexual Violence, Violence Against Children, Sexuality, Gender, Media. 
Em tempos recentes, tornou-se comum lermos notícias sobre violação sexual de crianças e adolescentes. ${ }^{1}$ Representantes do movimento social pelos direitos da criança e do movimento feminista afirmam que tal realidade era velada até há bem pouco tempo e reivindicam para si a conquista de sua publicização. De acordo com essa visão, portanto, a violência sexual apenas teria passado a ser conhecida após longas lutas ideológicas. Alguns chegam a afirmar, por exemplo, que a violência sexual comercial contra a criança era completamente desconhecida até o início da década de 1990, quando

adentrou a agenda brasileira como resultado das CPIs do extermínio de meninos e meninas de rua em 1991; da violência contra a mulher em 1992; da CPI da prostituição infanto-juvenil em $1993{ }^{2}$

Não há como negar que o tema da violência sexual contra crianças e adolescentes tem recebido grande atenção por parte da mídia, seja a mídia impressa (jornais diários e revistas semanais), seja a televisão. No ano de 1992, por exemplo, o jornal Folha de S.Paulo publicou quase 120 matérias sobre prostituição infantojuvenil no Brasil. ${ }^{3}$ Além da grande quantidade de matérias publicadas, o jornal denunciou o suposto número de meninas prostitutas em nosso país: em torno de 500 mil meninas. Outras informações contidas nos textos ajudaram a compor o quadro de

\footnotetext{
1 A denominação "violência sexual contra crianças e adolescentes" abrange uma diversidade de atos, tais como: estupro (dentro e fora da família), atentado violento ao pudor, prostituição, pornografia e tráfico para fins sexuais.

2 LEAL, Maria Lúcia. O impacto das ONGs no enfrentamento da exploração sexual comercial de crianças e adolescentes no Brasil. In: VASCONCELOS, Maria Gorete e MALlaK, Linda Simone. Compreendendo a violência sexual em uma perspectiva multidisciplinar. Carapicuíba-SP, Fundação Orsa Criança e Vida, 2002, p.17.

3 ANDRADE, Leandro Feitosa. Prostituição infanto-juvenil na mídia: estigmatização e ideologia. Tese de Doutorado, Departamento de Psicologia Social/ Pontifícia Universidade Católica de São Paulo, 2001, p.17.
} 
Violência sexual contra crianças na mídia impressa

uma realidade extremamente cruel: as crianças estavam sendo arregimentadas para a prostituição cada vez mais cedo; as vítimas já haviam vivido nas ruas; os cafetões e donos de boates não apenas forçavam as meninas a se prostituírem como as transformavam em escravas; os policiais, agentes da lei, muitas vezes torturavam as meninas; a família, desestruturada e desinformada, era responsabilizada pelo destino das filhas. ${ }^{4}$

Tendo como base esse retrato da situação da prostituição infantil feita pelo jornal - denominado por Andrade de "campanha moral" -, a tendência de muitas pessoas, que não conhecem a realidade da prostituição infantil senão pelas informações recebidas pela mídia, é achar que está ocorrendo um crescimento desse tipo de prática no país. Além disso, como na última década os jornais brasileiros têm apelado para a tática do chamado jornalismo investigativo, os casos acabam sendo apresentados como novidades, informações que estavam encobertas até então. A impressão, muitas vezes, é que a sociedade brasileira teria começado, de forma repentina, a ter conhecimento da situação.

Mas será possível que uma situação como a prostituição infantil fosse, realmente, desconhecida e viesse à tona de uma hora para a outra, chocando a todos? Aliás, será possível que a violência sexual contra crianças $e$ adolescentes fosse completamente invisível? Neste trabalho, a afirmação de que essa forma de violência era desconhecida até as últimas décadas do século XX deve ser interrogada a partir de notícias e reportagens publicadas em um jornal brasileiro de grande circulação, $O$ Estado de S.Paulo. ${ }^{5}$ Para tanto, um banco de dados cobrindo todo o século XX foi organizado a partir dos arquivos do jornal em microfilme e em papel, possibilitando a análise do material. Orientada pela bibliografia nacional e internacional, decidi-me por

\footnotetext{
4 ID., IB., pp.132-200.

${ }^{5}$ Essa mídia foi escolhida, pois, além da grande circulação, apresenta continuidade ao longo do século XX.
} 
fazer uma amostra (um ano a cada dez) a respeito dos três primeiros quartos do século e, a partir do ano de 1980, foram pesquisados todos os anos, sem exceção. As reportagens coletadas dizem respeito a alguma forma de violência sexual envolvendo menores de idade. Os textos foram separados de acordo com o tema (ou tipo de crime) retratado - como a mídia não segue rigidamente a conceituação legal, a classificação foi feita a partir dos valores implícitos na explicação ou justificativa do crime. Assim, ficaram definidos os seguintes grupos temáticos: incesto; crimes violentos cometidos por estranhos; crimes contra a honra; lenocínio e prostituição; pornografia infantil e pedofilia.

Apresento o material em dois blocos: o primeiro reporta ao início do século e o segundo ao final do período ${ }^{6}$, procurando chamar a atenção para a forma como os crimes sexuais eram noticiados e para os sentimentos sociais presentes nesses textos. $\mathrm{Na}$ conclusão, analiso as principais transformações na forma do jornal noticiar a violência sexual.

\section{Moralidade e repugnância}

No início do século, os tipos de crimes sexuais envolvendo menores de idade ${ }^{7}$ mais noticiados eram o estupro, os crimes contra a honra e a prostituição. O estupro de menores era noticiado como um crime revoltante. As crianças eram retratadas estritamente como vítimas, não há qualquer menção à criança ter

${ }^{6}$ Essa forma de apresentação dos dados foi preferida por colocar o foco nos sentimentos sociais predominantes. O período intermediário foi deixado de lado, pois é um momento de passagem entre uma forma mais envolvida de falar sobre a violência sexual para outra onde predomina o tom de distanciamento e denúncia.

7 A menoridade era considerada até os 21 anos de idade. Contudo, o Código Penal de 1890 dispensava um tratamento especial às vítimas de crimes sexuais menores de 16 anos - o artigo 272 definia que, até essa idade, a violência era considerada presumida, ou seja, os menores de 16 anos eram considerados incapazes de consentir com o ato sexual. No Código Penal de 1940, a presunção de violência passou a ser apenas até os 14 anos (art. 224). 
Violência sexual contra crianças na mídia impressa

"provocado" ou "consentido" o ato - para referir-se à criança vítima, eram usados termos como "victima de seus instinctos perversos", "pequena", "infeliz menina", "desgraçadinha".

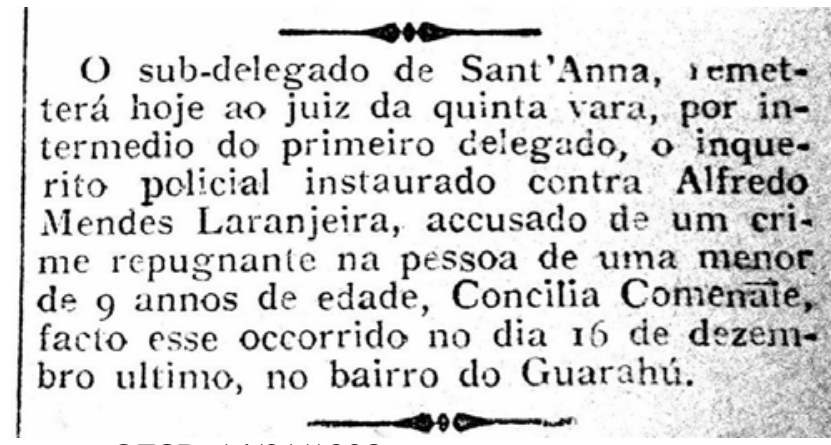

OESP, $14 / 01 / 1908$

Note-se que o jornal não afirma explicitamente o tipo de crime ocorrido, o caso é reportado com o auxílio de palavras vagas como "violentou-a", "praticou atos repugnantes", "atentado muito torpe". Dessa forma, o ocorrido é tratado como uma anormalidade e uma amoralidade, uma aberração. Apesar disso, poucas dessas situações são analisadas com profundidade. São raras as notícias posteriores ao acontecimento, comentando o desenrolar da situação - quando isso acontece, os textos expressam algum tipo de dúvida ou uma descoberta nova. Alcina, de 3 anos e meio de idade, foi deixada pela mãe aos cuidados de uma vizinha. Como esta também teve de sair,

Joaquim Jose Sant'Anna, de 78 annos de edade, e José Pontes Garcia, moradores no mesmo predio, individuos reputadamente perversos, aproveitaram-se da occasião, praticando actos repugnantes, de que foi victima a menor. [A suspeita de que isso havia ocorrido fora gerada por um] mal terrivel transmittido a Alcina. (OESP, 07/01/1920 e 09/01/1920) 
Dois dias após essa reportagem inicial, o jornal publicou o resultado da investigação: a menina não estava contaminada com nenhuma moléstia venérea, "o seu mal é uma simples consequencia da falta de hygiene".

Assim como os crimes de estupro, o incesto também é referido como um crime bastante grave e repugnante - contudo, são poucas as reportagens publicadas na mídia diária. Ou seja, apesar de pouco noticiado, a narrativa sobre incesto é sempre permeada pelos sentimentos de revolta e asco:

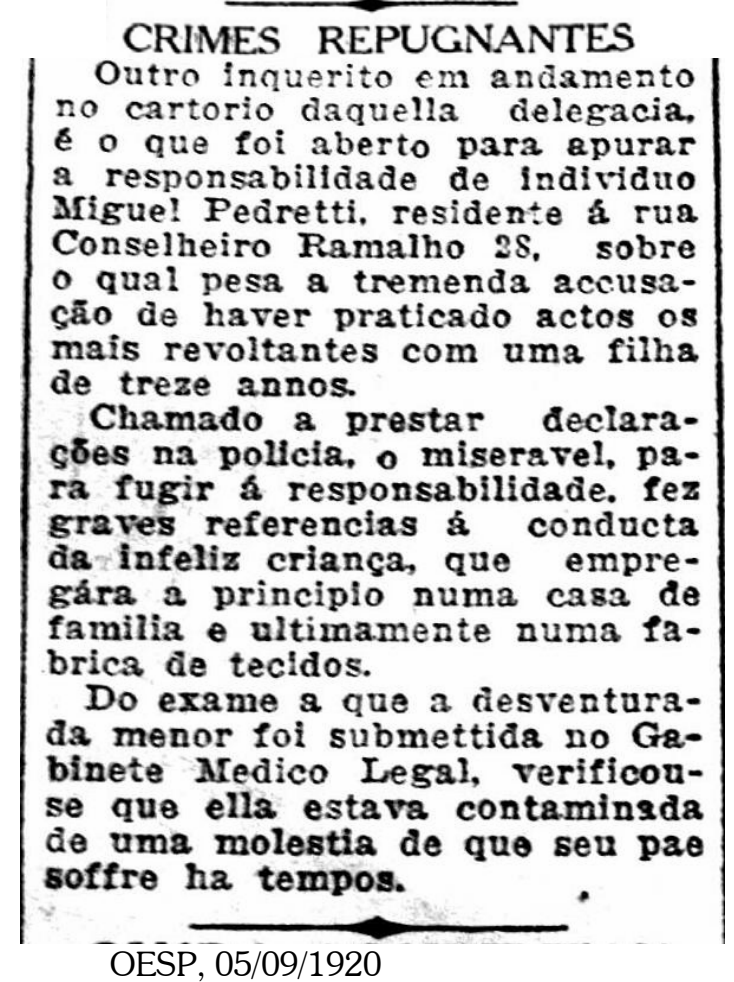

OESP, 05/09/1920 
Violência sexual contra crianças na mídia impressa

As notícias sobre incesto são interessantes não apenas por mostrar a recusa a essa forma de violência, mas também por dar indícios sobre a relação entre a violência sofrida dentro de casa $e$ a decisão pela entrada na prostituição:

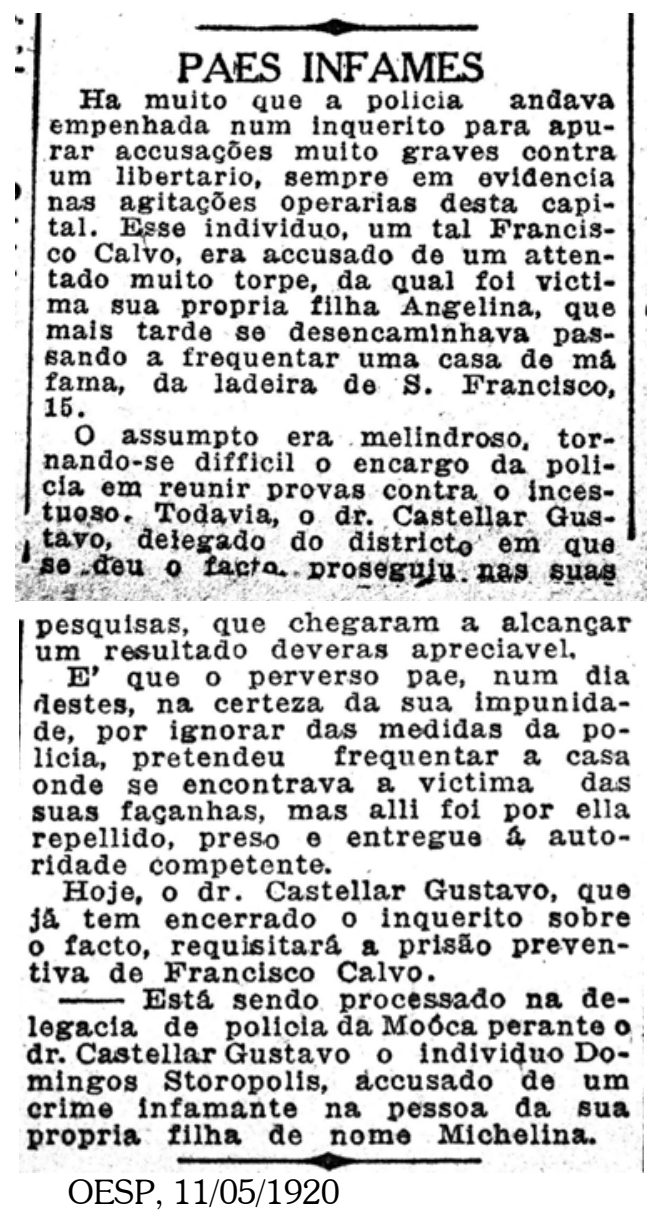


Fausto ${ }^{8}$ possui algumas informações sobre este ocorrido não constantes da matéria de jornal: o caso foi levado à polícia pela mãe de Angelina, esposa de Francisco Calvo. A queixa era a desconfiança da atitude de seu marido em relação à filha. Um mês depois, a menina foi encontrada trabalhando como prostituta em um bordel da ladeira de São Francisco e acusou o pai de tê-la estuprado há um ano, após espancar a mãe - quando da queixa à polícia, a moça apenas havia dito que o pai a ameaçava $e$ a impedia de namorar. No decorrer do processo, mudou o rumo de suas declarações novamente, afirmando que tudo era mentira $e$ que suas declarações anteriores foram baseadas no ódio pelo pai, que a prendia muito.

Outro tipo de crime bastante noticiado pelo jornal são os chamados "crimes contra a honra" - defloramento, sedução e rapto. Entretanto, ao contrário das notícias sobre estupro e incesto, as reportagens sobre os "crimes contra a honra" não expressavam o sentimento de repugnância e nem sempre mostravam a vítima como passiva. Em vários casos, o casal era preso, não apenas o rapaz. A figura do rapto consensual também estava presente nos jornais, o que mostra claramente a diferença entre o crime de sedução e o de "atentado torpe" ou "repugnante". A sedução também era um crime, mas, ao contrário do crime de estupro contra crianças, não parecia ser repugnante ou aberrante:

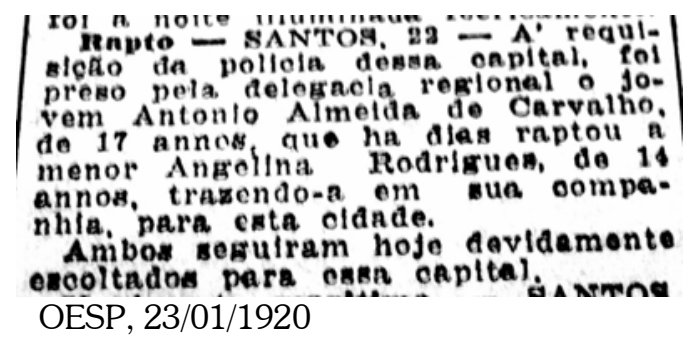

8 Fausto, Boris. Crime e cotidiano: a criminalidade em São Paulo (1880-1924). São Paulo, Editora da USP, 2001. 
Violência sexual contra crianças na mídia impressa

Esse tipo de crime, ao contrário do estupro e do incesto, está diretamente relacionado à desigualdade de gênero $e$, portanto, também diretamente relacionado à discussão a respeito da virgindade, da honra da mulher. Na passagem do século XIX ao XX, a manutenção da "honra feminina" era entendida como necessária à modernização do país. A família burguesa era o pilar no qual estava apoiado o discurso sobre essa modernização em um Brasil recém tornado República. ${ }^{9}$ Para tanto, a mulher deveria manter-se virgem até o casamento, garantindo o nascimento de uma prole sadia. Ao mesmo tempo, execrava-se a prostituição. $\mathrm{O}$ meretrício era, na visão corrente, o destino das moças impuras, daquelas que haviam sucumbido às "paixões" lascivas de seus namorados e amantes. As práticas de prostituição nas cidades em processo de modernização e de crescimento industrial eram denunciadas por jornalistas, médicos e criminologistas. ${ }^{10}$ Tornouse necessária a instituição de códigos morais de conduta, apropriados às moças honestas, à medida que mulheres de todas as classes sociais passaram a ocupar o espaço público, seja trabalhando nas fábricas, seja participando das novas formas de lazer que a cidade propiciava. A prostituição recebeu novos significados culturais; grupos de especialistas (médicos-legistas, criminologistas e jornalistas) viam-na como uma ameaça de corrupção para a juventude, principalmente para as jovens acostumadas à vida no lar. Virgindade, casamento e maternidade passaram a ser temas mais discutidos, no sentido de incrementar a formação do caráter da mulher. Ao mesmo tempo, a prostituição era construída como um "fantasma" que ameaçava a moralidade. ${ }^{11}$

9 CAUlFIELD, Sueann. Em defesa da honra: moralidade, modernidade e nação no Rio de Janeiro (1918-1940). Campinas-SP, Editora da Unicamp/Centro de Pesquisa em História Social da Cultura, 2000.

${ }^{10}$ RAGO, Margareth. Imagens da prostituição na Belle Epoque paulistana. Cadernos Pagu (1), Núcleo de Estudos de Gênero - Pagu/Unicamp, 1993, p.32.

${ }^{11}$ ID., IB., p.34. 
Se, nas primeiras décadas do século XX, a mulher podia desfrutar de uma liberdade maior do que no final do século anterior, a prostituição era mostrada como um contra-ideal, um limite a essa liberdade. O Brasil, e São Paulo em especial, passavam por um grande crescimento urbano $e$ industrial, as possibilidades da vida social expandiam-se, engendrando a necessidade de mostrar às moças o que, nessa nova configuração social, era aceitável e o que ultrapassava os limites. A figura da prostituta era o limite do inaceitável, o caminho a ser evitado e, portanto, acabava por demarcar o aceitável, reafirmando a posição da mulher como "futura missionária da pátria e futura formadora dos cidadãos e da raça".

O contexto social dessa época, quando a sociedade paulista assistia à polêmica em relação ao defloramento e à prostituição, explica essa visibilidade. Obviamente, não era por mero acaso que os jornais estavam noticiando esses crimes. A passagem do século XIX para o século XX e as primeiras décadas deste foram épocas de mudanças profundas no cotidiano da cidade. O número de moradores quadruplicou entre 1890 e 1900, passando de 64.934 para 239.820 habitantes; entre 1900 e 1920 a população duplicou, chegando a 579.033; em 1940, o número de paulistanos já era de 1.326.261. A imigração de europeus contribuiu bastante para esse crescimento: mais de 2.000 .000 entraram na cidade entre 1888 e 1928. ${ }^{12}$

Nas páginas de O Estado de S.Paulo, o lenocínio era um problema relacionado aos imigrantes que chegavam às centenas no território nacional. O "tráfico de brancas", como era chamado, preocupava muito a sociedade da época. A chegada do paquete italiano Veronese, vindo de Coruña, levou a imprensa a reclamar pela repressão a esse tipo de tráfico - no barco, vinham diversas menores escravizadas (OESP, 02/10/1908). Mas não apenas os navios que traziam menores eram alvos de críticas; estrangeiros

\footnotetext{
${ }^{12}$ BESSE, Susan. Modernizando a Desigualdade: reestruturação da ideologia de
} gênero no Brasil, 1914-1940. São Paulo, Editora da USP, 1999, p.17. 
Violência sexual contra crianças na mídia impressa

habitantes no Brasil eram acusados e expulsos do território nacional (09/04/1930). Contra o húngaro Pedro Huber proprietário do "cabaret" e bar Estrella - havia uma ordem de expulsão:

foi acusado por sua propria filha Catharina, a quem obrigava a entregar-se ao lenocínio, no estabelecimento de sua propriedade, e a quem extorquia o dinheiro que ella conseguia dessa forma. $(18 / 03 / 1930)$

As meninas que permaneciam em casas de tolerância ou "casa de uma mulher de má conducta", como a menor de sete anos de idade, Maria Teodora da Conceição (03/01/1908), eram alvos de preocupação. Estrangeiras também eram encontradas nesses estabelecimentos: uma menor de 16 anos, cujo nome fictício de Maria Luiza Podestad foi dado em uma casa de tolerância, "fez graves accusações á sua governante, que pretendia exploral-a, desviando-a para um mau caminho, com o proposito de auferir lucro, nessa exploração repugnante". (05/02/1920)

Mesmo em menor número, os casos de meninos implicados na prostituição também estão presentes no jornal:

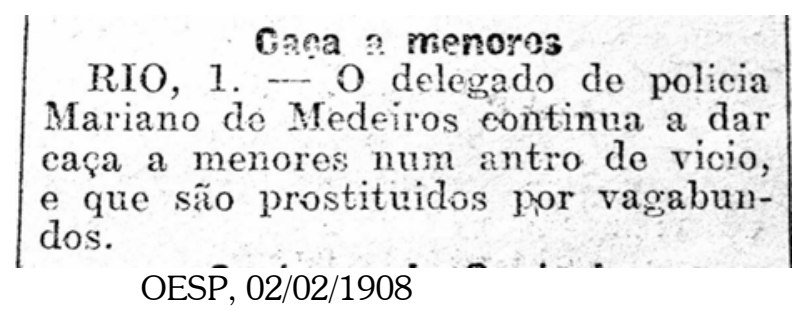

As reportagens do início do século não discutiam as características das moças que eram traficadas ou que se ofereciam à prostituição; a família tampouco estava presente nos textos. Os alvos eram os imigrantes, os "perversos" que se ocupavam em desviar menores. A presença de menores de idade na prostituição era abordada como uma questão ligada à prostituição adulta. Em 
Tatiana Savoia Landini

outras palavras, os artigos publicados não apresentam a prostituição infantil como um problema específico, mas sim como um "agravante" da prostituição adulta.

\section{Distanciamento e denúncia}

No final do século $\mathrm{XX}$, o estupro $e$ a prostituição continuaram a ser dois tipos de crime bastante reportados pelo jornal. Entretanto, os pressupostos a respeito das causas desses crimes e a narrativa dos fatos mudaram de forma acentuada.

No final do século, as matérias sobre estupro cada vez mais relacionam esse tipo de crime à violência física, ao assassinato, às facadas $e$ aos estrangulamentos. A expressão de recusa está expressa não apenas em relação ao estupro em si, mas também à violência que o acompanha: os estupradores violentam suas vítimas, muitas vezes meninas pequenas, se elas tentam reagir, são mortas e seus corpos são jogados em poços no fundo do quintal ou enterradas no chão da casa do próprio estuprador. Os estupradores retratados, nessa época, muitas vezes, são também traficantes de drogas.

Os estupradores são representados como pessoas violentas e o tipo de crime que cometem é um ultraje aos olhos da população, que os lincha sem piedade, mesmo na prisão. $\mathrm{O}$ estupro não é um crime aceito nem mesmo por criminosos. Aliás, é possível dizer que o estupradores são "linchados" pelo próprio jornal, que passou a transformar esses casos em escândalos jornalísticos, esmiuçando a vida dessas pessoas em reportagens em série. ${ }^{13}$

\footnotetext{
${ }^{13}$ Nesse sentido, é notório o caso conhecido como "Escola Base". O jornal concorrente de O Estado de S.Paulo, a Folha de S.Paulo, publicou uma série de reportagens acusando os donos da referida escola de terem abusado sexualmente dos alunos $e$ os fazerem participar de orgias. $\mathrm{O}$ donos tiveram sua escola depredada $e$, ao final, nenhuma das acusações foi provada. Tanto $O$ Estado de S.Paulo quanto a Folha de S.Paulo foram processados por danos morais e materiais, em função de acusações infundadas.
} 
Violência sexual contra crianças na mídia impressa

Na década de 1990, a mudança em relação à forma como a violência sexual é retratada mostra uma nova sensibilidade social: os crimes de estupro, antes alvo de poucas reportagens, passaram a ser escândalos jornalísticos. Alguns casos são apresentados, analisados, e seus desdobramentos passados ao leitor diariamente. O leitor de O Estado de S.Paulo conheceu muito sobre Marcelo, em 1992. O "maníaco sexual" ou "psicopata da BR 101", como ficou conhecido, tinha 25 anos, foi preso no Rio de Janeiro e confessou ter assassinado e violentado 14 garotos, com idades entre 5 e 13 anos.

Marcelo era muito religioso,

ele contou que freqüentava a Igreja Universal do Reino de Deus há cinco anos. Para tentar justificar seus crimes, disse que sempre ouviu dos pastores da Igreja Universal que as crianças menores de 13 anos, quando mortas violentamente, iam para o céu e se juntavam a Deus. (16/02/1992). [Era, também, apaixonado por meninos] como ele mesmo disse à Polícia, Marcelo tinha preferência por meninos bonitos, a quem seduzia com propostas de um lanche e algum dinheiro. (19/02/1992).

Além do próprio Marcelo, o jornal entrevistou sua mãe, que afirmou ter começado a desconfiar de que alguma coisa estava errada numa noite que o filho saiu com um facão de cozinha para cortar bananas na casa de um vizinho e voltou sem as bananas $e$ com a faca suja de sangue (20/02/1992).

O caso de Marcelo é interessante para mostrar um outro ponto característico da década de 1990: as causas de crimes como esse começaram a ser mais bem investigadas e a sanidade mental dos "maníacos" passou a ser questionada. Neste caso, o psiquiatra que fez o diagnóstico de Marcelo acreditava que ele era um "psicopata explícito", um doente de alta periculosidade que voltaria a cometer outros crimes caso fosse solto. O passado dos criminosos é levado em consideração, trazendo à tona a questão das conseqüências do abuso de crianças: ele "é filho de pais 
pobres, fugiu de casa aos 8 anos e foi estuprado aos 9. 'A história desse menino teria de acabar nessa explosão de violência patológica"” (23/02/1992).

Essa é uma mudança bastante significativa na forma de retratar a violência sexual, que passa a ser "analisada", entendida como algo que requer mais do que uma simples expressão de horror e recusa. Não apenas a vida do estuprador passou a ser analisada $e$ as causas do crime questionadas, mas a vítima também precisa ser atendida, tratada, "a violência sexual não deve ser encarada apenas como um caso de polícia, mas como uma questão de saúde" (OESP, 02/02/1990).

A reportagem analítica também foi utilizada pelo jornal no final do século XX para tratar os crimes de incesto. Poucos casos são efetivamente relatados; na maioria das reportagens, o problema do incesto é desvelado em matérias que falam de forma mais ampla sobre a violência contra a criança:

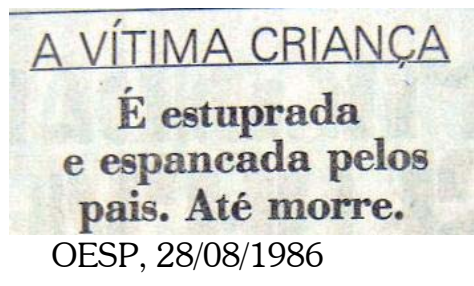

No texto, que versa sobre inúmeras violências que vitimam crianças, uma psiquiatra do Instituto da Criança informa que

a maioria dos estupros na infância é, na verdade, praticado pelos próprios pais. Na Delegacia da Mulher de São Paulo, eles representam $30 \%$ dos casos. Em Porto Alegre, há um por dia. [Outro psiquiatra confessa-se impressionado com] os relatos de adultos - especialmente mulheres - que passaram por abusos sexuais quando crianças. 
Violência sexual contra crianças na mídia impressa

Nas últimas décadas do século XX, é possível perceber uma "distância" no tratamento da questão, nos textos que relatam casos específicos de incesto. O texto passa a imagem da busca da neutralidade, não há mais o uso de palavras como "maus instintos", "crime bárbaro" ou "repugnante":

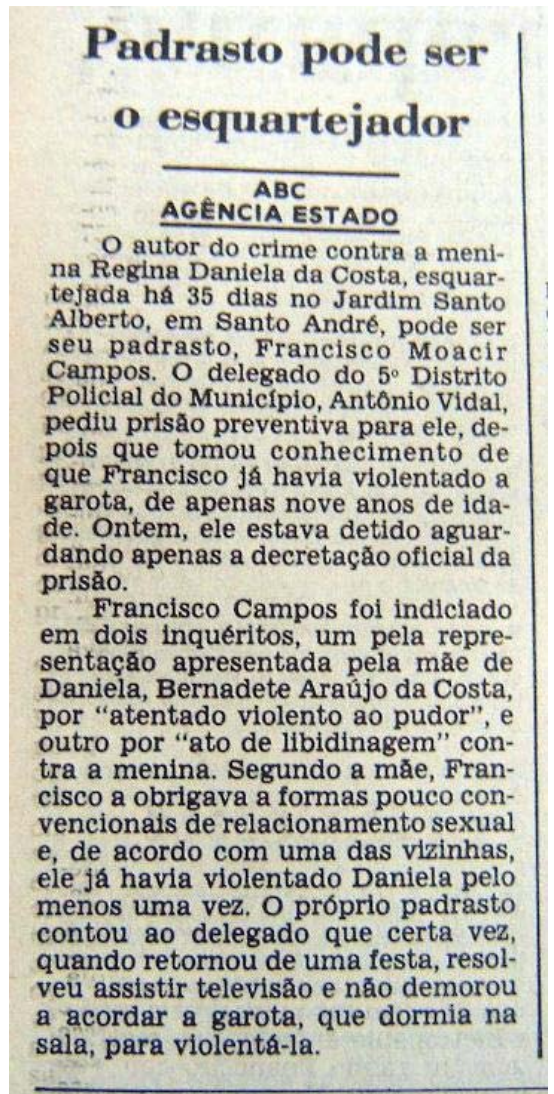

OESP, 04/07/1987

Em relação à prostituição, também são bastante significativas as mudanças na forma como a questão é reportada. Na década de 1980, em comparação com o início e meio do 
século, as reportagens passaram a analisar mais detidamente a questão. Cada vez mais, os textos sobre prostituição passam a enfocar a pobreza - e não mais o desvirginamento, a menina perdida ou poluída - como fator determinante para que a criança ou adolescente comece a se prostituir. Nesse sentido, ao desvincular a prostituição da questão moral, cresce o número de reportagens sobre meninos "vítimas do comércio do sexo".

Reportagem intitulada "Meninos prostituem-se em Brasília" (15/10/1989) afirma que dezenas de meninos, de 10 a 15 anos, prostituem-se na Rodoviária da capital federal, próxima ao Palácio do Planalto. O texto tem um tom apelativo de denúncia:

As aproximadamente 60 crianças que vivem na rodoviária, esquecidas pela família e desprezadas pela sociedade, já viraram delinqüentes e são o alvo preferido de homossexuais e pedófilos (adultos que abusam sexualmente de crianças).

Outra reportagem, conta a história de como um garoto - Coruja iniciou-se na prostituição aos dez anos de idade: pobre, carente e inocente, o menino foi morar nas ruas por influência de um primo. Uma noite, enquanto procurava um lugar para dormir na rodoviária, um homem o convidou para um programa. Sem saber ainda de que se tratava o "programa", Coruja, "empurrado pela curiosidade e pela inocência", acabou acompanhando o homem "e teve, com dez anos de idade, sua primeira experiência homossexual". 
Violência sexual contra crianças na mídia impressa

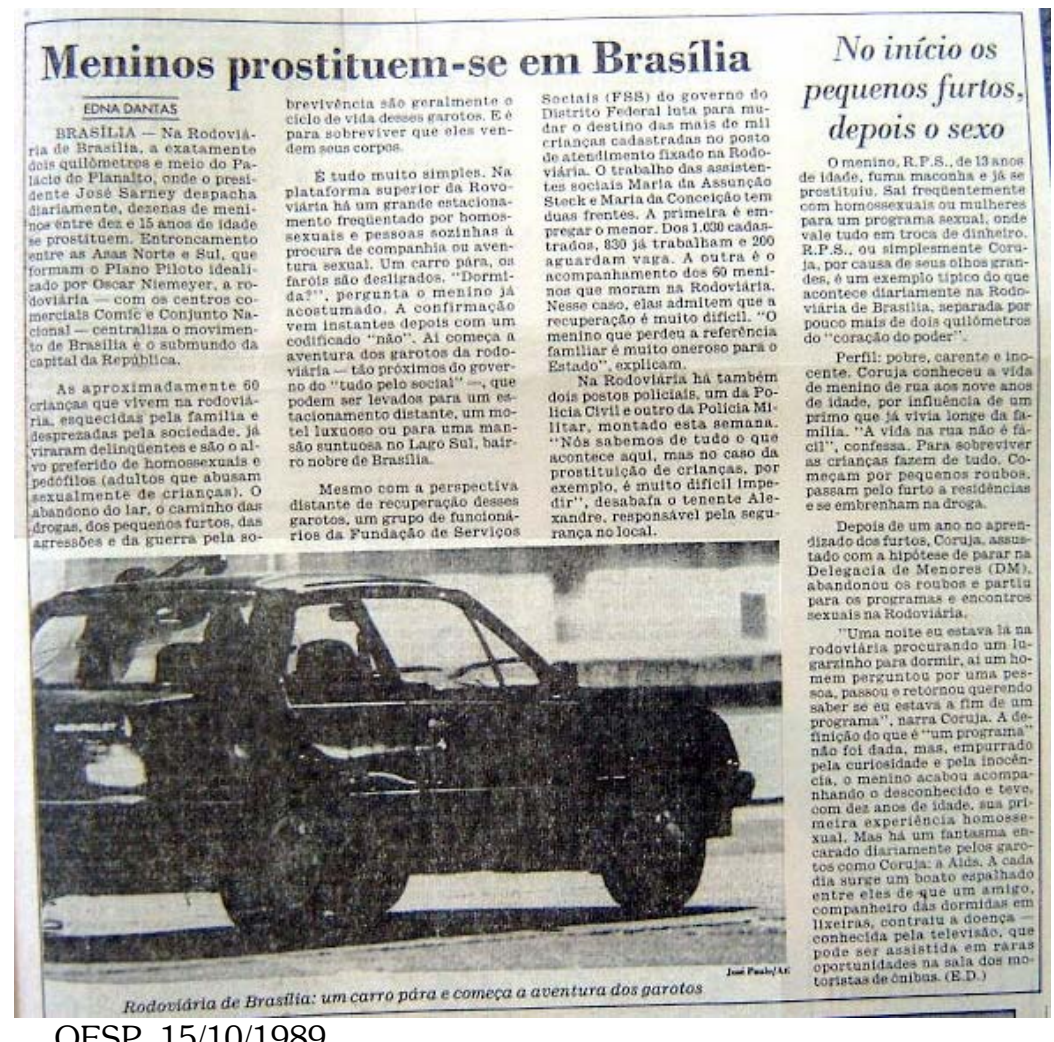

OESP, $15 / 10 / 1989$

Em 1993 foi instituída a CPI (Comissão Parlamentar de Inquérito) da Prostituição Infanto-Juvenil. ${ }^{14} \mathrm{Em}$ decorrência, vários textos acompanharam os procedimentos e informavam o leitor as descobertas, principalmente os números "escandalosos": segundo

\footnotetext{
${ }^{14}$ Uma análise dos depoimentos feitos à CPI da Prostituição Infanto-Juvenil pode ser encontrada em SouzA, Sônia M. Gomes. A exploração sexual de crianças e adolescentes segundo os depoentes da CPI (1993-1994). In: LiBóRIO, Renata Maria Coimbra e SouzA, S. M. G. (orgs.) A Exploração Sexual de Crianças e Adolescentes no Brasil - reflexóes teóricas, relatos de pesquisas e intervenções psicossociais. São Paulo/Goiânia, Casa do Psicólogo/Universidade Católica de Goiás, 2004.
} 
o Ministério do Bem Estar Social, naquele momento, o Brasil tinha cerca de 500 mil menores prostituídos (OESP, 02/09/1993).

Além dos números, o jornal publicou um "panorama geral" da prostituição no Brasil, utilizando pesquisas realizadas por organizações não governamentais, nacionais e internacionais. Nesse sentido, o leitor foi informado de que "a prostituição infantil no Brasil tem dimensões diferentes de acordo com as atividades econômicas predominantes em cada região" (OESP, 17/03/1999), além das características da prostituição em cada uma das regiões. ${ }^{15}$ Complementando esse quadro, o jornal publicou várias reportagens sobre a atuação das autoridades no combate à prostituição de meninas e meninos: projetos estaduais de combate à prostituição infantil, um telefone nacional para denúncia anônima, diversas blitz da polícia militar, etc.

Além desses tipos de violência sexual - estupro, incesto $e$ prostituição infantil -, a partir da década de 1990, a mídia começou a publicar reportagens a respeito das "novas modalidades" ainda ausentes nos noticiários: a pornografia infantil $e$ a pedofilia.

O crescimento do número de reportagens publicadas sobre pornografia infantil e pedofilia deu-se a partir da segunda metade da década de 1990. A pedofilia é retratada principalmente como um problema relacionado à pornografia infantil. Duas características são comuns a ambas as categorias, segundo a forma como são retratadas pelo jornal: a idéia de rede "denúncias de ramificação no Brasil de uma rede mundial de pedofilia" (OESP, 20/10/1998) - e o número "absurdo" tanto de pessoas que integram essas redes, quanto de imagens trocadas pelos pedófilos - "cerca de 600 pessoas foram presas durante uma blitz contra a pornografia infantil" (OESP, 18/06/1997).

\footnotetext{
${ }^{15}$ As reportagens afirmavam, por exemplo, que os garimpos da região norte propiciavam as formas mais violentas de exploração sexual e incluíam o cárcere privado, a venda e o tráfico de menores, leilões de virgens, mutilações $e$ desaparecimentos. No Norte, concentrava-se o turismo sexual portuário, no Sul, a exploração de meninos e meninas de rua.
} 
Violência sexual contra crianças na mídia impressa

Entretanto, a pedofilia não era identificada somente com a pornografia infantil. Uma terceira característica importante aparecia: a pedofilia passou a ser retratada como uma doença $e$, nesse sentido, acabou sendo usada como uma justificativa para explicar crimes chocantes ou cometidos por pessoas famosas $e$ reconhecidas que, de outra forma, não deveriam ser criminosas: por exemplo, o cientista americano Daniel Gajdused, ganhador do Nobel de medicina (OESP, 30/04/1997), o filósofo francês Gérard Lebrun (OESP, 20/01/1997) e o autor britânico Arthur C. Clarke (OESP, 08/04/1998). ${ }^{16}$

Além dos temas pornografia infantil e pedofilia, que não eram tratados até as últimas décadas do século, outro tipo de reportagem aparece apenas no final do período - é o que classificamos como textos "gerais", aqueles que não tratam de um caso ou acontecimento de forma específica, mas buscam analisar a situação da violência sexual de forma ampla. Nesse sentido, o texto busca sempre uma generalização e a objetividade dos dados transmitidos ao leitor. Para tanto, são utilizadas fontes de informação consideradas confiáveis, tais como profissionais ou especialistas que trabalham diretamente com esse tema, sejam policiais, psicólogos, médicos, advogados ou funcionários de ONGs.

Alguns acontecimentos, como a inauguração da primeira Delegacia de Polícia de Defesa da Mulher, em 07/08/1985, motivaram a publicação de reportagens sobre esse tema. Ao fazer referência à inauguração, o jornal afirmou que a delegacia

\footnotetext{
${ }^{16}$ Ao utilizar o termo pedofilia para fazer referência a crimes cometidos por pessoas famosas e, principalmente, ao "explicar" esses crimes com base em problemas psicológicos dos acusados, o jornal acabou por fazer uma recorte de classe: os autores de crimes sexuais são denominados de uma forma diferente de acordo com a classe social a que pertencem. Essa questão de classe social do pedófilo já foi analisada por mim, cf. LANDINI, Tatiana Savoia. Pedofilia e pornografia infantil: algumas notas. In: PISCITELLI, Adriana et alii. (orgs.) Sexualidades e Saberes: convenções e fronteiras. Rio de Janeiro, Garamond, 2004 e Pedófilo, quem és? A pedofilia na mídia impressa. Cadernos de Saúde Pública, vol. 19, suplemento 2, 2003.
} 
"começou a funcionar ontem com casos de sedução, espancamento e até estupro de uma menina de quatro anos" (08/08/1985). Adiciona, ainda, que o último "é o caso mais grave ocorrido ontem". No dia seguinte, 09/08/1985, o jornal voltou a abordar o assunto: "Aumentam os casos da nova delegacia".

As reportagens analíticas sobre a violência sexual trazem também muitos dados quantitativos, por exemplo: cem mulheres são violentadas por mês em São Paulo - é comum o estupro com autoria conhecida, principalmente envolvendo crianças $e$ adolescentes (11/04/1992); pais são responsáveis por $50 \%$ dos estupros em São Paulo (05/12/1992); Violência familiar afeta 500 mil crianças (08/10/1993); São Paulo e Rio de Janeiro lideram exploração sexual infantil - em cada estado foram registrados 268 casos até setembro (08/11/1999).

Algumas vezes, essas reportagens são ilustradas por fotos que emprestam uma imagem apelativa à notícia, buscando sensibilizar os leitores:

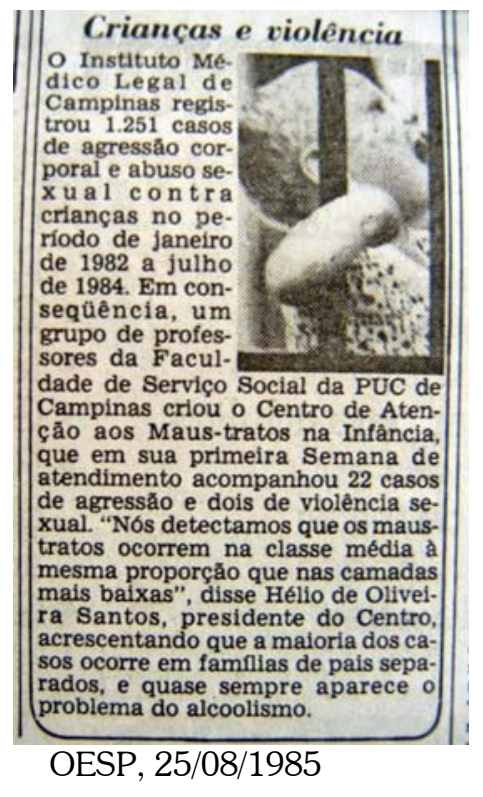


Violência sexual contra crianças na mídia impressa

A reportagem acima mostra a foto de uma criança gritando, atrás de barras. O texto que a acompanha afirma que 1.251 casos de agressão corporal e abuso sexual contra crianças foram registrados pelo Instituto Médico Legal de Campinas no período de janeiro de 1982 a junho de 1984 (25/08/1985).

Além dos números de casos registrados ou denunciados, o jornal também publicou diversas reportagens afirmando que houve aumento nos casos de violência contra crianças: Violência sexual contra crianças cresce no país - a notificação de casos de violência sexual contra crianças aumentou drasticamente nesta década na cidade de São Paulo (28/07/1990); Pesquisa revela crescimento de violência contra menores no Rio - em 1998, a média mensal era de 250 denúncias; em 1999 subiu para 300 (25/07/1999).

\section{Conclusão}

A violência sexual contra crianças e adolescentes, em suas diversas modalidades, é um assunto tratado pela mídia impressa pelo menos desde o início do século XX. Incesto, estupro e prostituição são, há um século, temas de diversas reportagens. Entretanto, a forma de tratar a questão e o enfoque do texto sofreram mudanças significativas - a forma como falava-se sobre a violência sexual nas décadas de 1910 e 1920, por exemplo, não é a mesma utilizada pelos jornalistas do final do século XX. Vale a pena pontuar algumas dessas mudanças.

Em primeiro lugar, é patente o crescimento no número de textos sobre violência sexual publicados pelo jornal, como é possivel visualizar na tabela a seguir: 
Tatiana Savoia Landini

Tabela 1 - Reportagens Publicadas no OESP ${ }^{17}$

\begin{tabular}{|l|c|l|c|c|c|}
\hline Ano & $\begin{array}{l}\text { Repor- } \\
\text { tagens }\end{array}$ & Ano & $\begin{array}{l}\text { Repor- } \\
\text { tagens }\end{array}$ & Ano & $\begin{array}{l}\text { Repor- } \\
\text { Tagens }\end{array}$ \\
\hline 1908 & 12 & 1982 & 39 & 1992 & 71 \\
\hline 1920 & 27 & 1983 & 8 & 1993 & 43 \\
\hline 1930 & 4 & 1984 & 10 & 1994 & 40 \\
\hline 1940 & 1 & 1985 & 20 & 1995 & 33 \\
\hline 1950 & 3 & 1986 & 15 & 1996 & 59 \\
\hline 1960 & 17 & 1987 & 11 & 1997 & 38 \\
\hline 1970 & 5 & 1988 & 19 & 1998 & 26 \\
\hline 1975 & 3 & 1989 & 13 & 1999 & 38 \\
\hline 1980 & 11 & 1990 & 20 & Total & 597 \\
\hline 1981 & 14 & 1991 & 48 & & \\
\hline
\end{tabular}

Gráfico 1 - Reportagens Publicadas no OESP

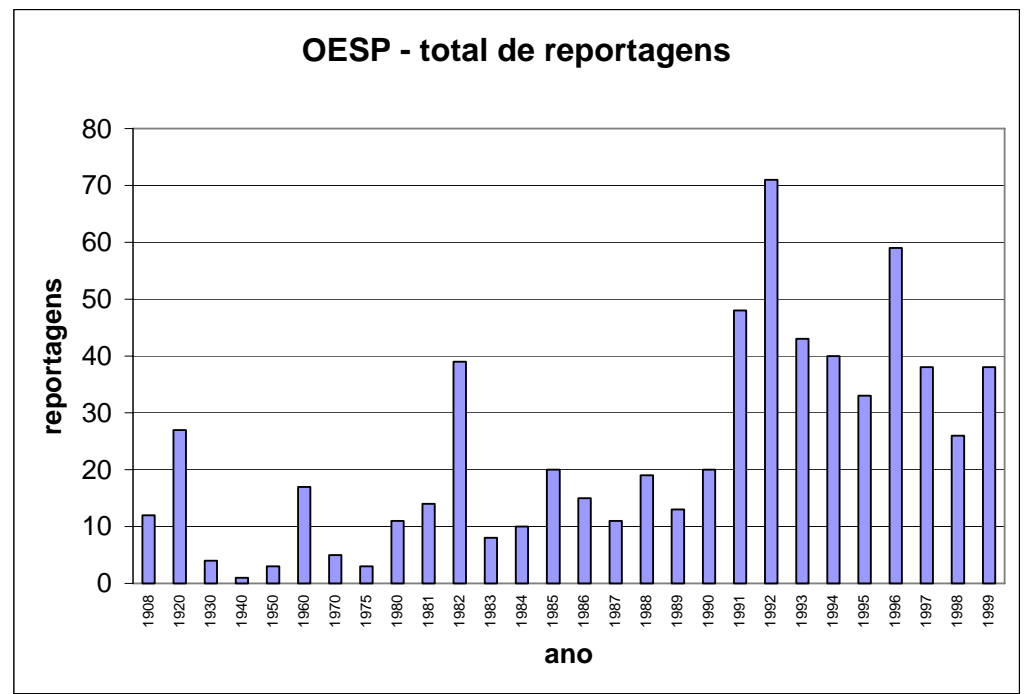

${ }^{17}$ Não foi possível coletar as reportagens referentes ao ano de 2000 em função de problemas na base de dados. 
Violência sexual contra crianças na mídia impressa

Uma segunda mudança foi o aumento nos tipos de violência retratados. Ao longo do século, formas de violência não discutidas anteriormente entraram para o rol dos crimes noticiados recorrentemente pelo jornal, principalmente a pornografia infantil e a pedofilia. Além destas, passou a haver também um maior detalhamento, por exemplo, da prostituição infantil. Se, no início $e$ no meio do século, a imprensa limitava-se a denunciar alguns casos de lenocínio ou prostituição, no final do período, fala-se em várias modalidades relacionadas à exploração sexual comercial: leilões de virgindade, cárcere privado em bordéis, turismo internacional, turismo nacional, etc.

Em terceiro lugar, nota-se uma maior profundidade na análise dos casos. O espaço destinado aos textos sobre violência sexual tornou-se maior. Assim, o jornalista não se limitava a "dar a notícia", mas fazia uma análise e entrevistava especialistas que contribuíam com a leitura e entendimento das causas. Houve, também, continuidade no acompanhamento de vários casos, o que raramente acontecia no início do século. Nesse sentido, alguns casos são transformados em escândalos e sobre eles são publicadas notícias praticamente diárias.

Uma quarta diferença na forma de noticiar a violência é a própria linguagem utilizada. Nos primeiros três quartos do século são mais comuns expressões como "homem de maus instintos", "crime perverso", "ato repugnante", ou seja, palavras mais ligadas à moralidade, ao que era socialmente aceitável ou inaceitável. A partir da década de 1980, o noticiário sobre violência sexual passou a ser revestido pela linguagem científica e pelos dados quantitativos.

Por fim, uma quinta diferença diz respeito à forma como a mídia transmite ao leitor a possível freqüência com que a violência sexual ocorre. Se no início do século as reportagens publicadas eram exclusivamente sobre casos específicos, esporádicos, a introdução de textos gerais sobre a temática da violência sexual transmite a mensagem de que os crimes sexuais são eventos 
comuns, cotidianos, e que havia uma sub-notificação de sua ocorrência.

Em suma, a impressão transmitida pelo jornal analisado é que o Brasil estaria passando por um período de barbarização, de aumento desmesurado da violência. O que no início do século era visto como um problema extra-ordinário, ocasional, no final do período passou a ser entendido como algo que ocorre regularmente e vitima grande parte das crianças $e$ adolescentes brasileiros.

Norbert Elias, em $O$ Processo Civilizador, analisa as possíveis direções tomadas historicamente pelas sociedades européias. Segundo ele, a pacificação é um dos resultados do processo da civilização, tanto em nível dos Estados, quanto das pessoas como indivíduos, uma transformação civilizadora, profundamente arraigada, da estrutura inteira da personalidade. ${ }^{18}$

Entretanto, como lembra o autor, esse processo de pacificação nunca está completo, e sempre está ameaçado. ${ }^{19}$ Considerando o retrato da violência sexual transmitido ao leitor d'O Estado de S. Paulo, não seria mais cabível pensar que o Brasil está passando por um processo de descivilização, de aumento da violência?

Considerando que estamos falando de um aumento de visibilidade da violência sexual, e não um crescimento efetivo no número de casos, a resposta é negativa. O fato de termos mais conhecimento da ocorrência de crimes como estupro, prostituição $e$ pornografia infantil não caracteriza um processo de descivilização. Ao contrário, as mudanças ocorridas ao longo desses cem anos apontam para um processo da civilização, tal qual retratado por Elias para a Europa. ${ }^{20}$

\footnotetext{
${ }^{18}$ ELIAS, Norbert. Os Alemães: a luta pelo poder e a evolução do habitus nos séculos XIX e XX. Rio de Janeiro, Zahar, 1997, p.163.

${ }^{19}$ ID. IB., p.161.

${ }^{20}$ Um processo da civilização brasileira está ainda por ser escrito.
} 
Violência sexual contra crianças na mídia impressa

É possivel perceber maior igualdade na balança de poder entre os $\operatorname{sexos}^{21}$, em outras palavras, uma diminuição na desigualdade entre os gêneros. Isso contribui diretamente para uma das transformações analisadas acima: os crimes contra a honra - defloramento, sedução e rapto - deixam de ser assunto da mídia nas últimas décadas do século XX. A virgindade, menos valorizada do que no início e no meio do século, deixou de ser uma razão para que meninas e moças tentem provar seu bom comportamento nos tribunais. Além disso, mais independentes, as mulheres reconhecem seus próprios desejos e ações, o que faz com que denunciem mais casos não relacionados à honra. ${ }^{22}$

Além disso, também de acordo com as características do processo de civilização, é possível perceber um aumento da distância entre as gerações ao longo do período. Isso não significa distância sentimental, mas, ao contrário, um reconhecimento das particularidades das diversas fases da vida e, assim, um maior cuidado $e$ atenção às necessidades. Esse ponto pode ser percebido nos direitos das crianças e adolescentes, aceitos $e$ formalizados nas tantas Convençóes e acordos nacionais $e$ internacionais: o direito à proteção, ao desenvolvimento saudável, à educação, chegando até ao direito de brincar.

Em relação à violência sexual, esse ponto introduz uma grande mudança. Elias ${ }^{23}$ afirma que o tema "sexo" era tratado com naturalidade em livros para crianças - os escritos de Erasmo

\footnotetext{
${ }^{21}$ Maior igualdade na balança de poder entre os sexos não significa, em absoluto, que não exista desigualdade de gênero no Brasil, mas tão somente que essa desigualdade diminuiu no decorrer do século XX.

${ }^{22}$ É claro que essa é uma visão geral, uma tendência, os crimes contra a honra não desapareceram por completo e a justiça é usada como forma de resolver problemas entre os casais - é o caso das inúmeras denúncias de estupro feitas por esposas que, após a primeira intervenção da polícia, retiram a queixa acreditando que seus maridos "aprenderam a lição", mas essa é uma questão que não diz respeito a este texto.

${ }^{23}$ Elias, N. The Civilizing Process - sociogenetic and psychogenetic investigations. Massachusetts, Blackwell, 2000.
} 
de Rotterdam (século XVI), por exemplo, falavam sobre prostitutas e sobre as casas em que elas viviam. No século XX, o "sexo" passou a ser um assunto que deveria ser evitado na presença de menores de idade, quiçá em livros destinados a eles. Se esse é um tema a ser evitado, a publicidade em torno da violência sexual pode ser entendida como um fator complementar - se o simples falar sobre sexo "macula a alma" da criança, forçá-la a atos sexuais é, então, muito mais grave.

Em termos legais, reconhece-se que a criança deve ser protegida de todas as formas de abuso e exploração sexuais pouco a pouco, a legislação vai incorporando artigos $e$ dispositivos que diferenciam cada vez mais a violência sofrida por crianças, adolescentes e adultos. Em termos práticos, os grupos sociais que lutam pela defesa destes direitos ganharam força $e$ visibilidade, mostrando de forma crescente que a violência sexual existe e deve ser denunciada e combatida.

Concluindo, pode-se afirmar que houve uma mudança profunda na forma de entender a violência sexual cometida contra menores de idade - a ênfase, antes colocada na questão de gênero, passou a ser posta na idade, ou seja, se antes a violência era entendida como um problema relacionado à desigualdade entre homens e mulheres, no final do século XX ela passou a ser vista muito mais como uma questão relacionada à desigualdade entre crianças e adultos. Em outras palavras, houve uma mudança de enfoque de gênero para geração. Nesse sentido, o que antes constituía uma única categoria - a violência sexual, seja contra crianças seja contra adultos - passou a constituir dois grupos analíticos - a violência sexual contra adultos e a violência sexual contra crianças.

Os "crimes contra a honra" e a prostituição são atos que aparecem nos textos do jornal sem evocar qualquer tipo de sentimento de repugnância. A questão é moral: a relação sexual antes do casamento desonra a moça. A prostituição, também considerada uma desonra, fere a reputação das moças de "boa" 
Violência sexual contra crianças na mídia impressa

família, é o destino das impuras, as que sucumbiram aos desejos masculinos e "perderam-se".

No final do século, os textos sobre prostituição adquirem um outro tom, um outro enfoque: as meninas e meninos passaram a ser vistos como vítimas da pobreza e do abandono, não mais da desonra sexual. Nesse período, o jornal deixa de publicar reportagens sobre os "crimes contra a honra",. em seu lugar aparecem os textos sobre pedofilia e pornografia infantil, dois tipos de crime que só existem se a vítima for menor de idade. A justificativa não é mais a necessidade de proteção da moça, mas a proteção da criança, menina ou menino.

Se os "crimes contra a honra" e a prostituição eram representados pelo jornal como atos que não geravam repugnância, os textos sobre estupro e incesto, ao contrário, ao longo de todo o século XX transmitiram o sentimento de horror, de um crime execrável. Em relação a eles, é possível afirmar que sempre enfatizaram a idade das vítimas, sempre estiveram, de alguma forma, ligados à questão da idade. Contudo, há uma mudança próxima à que chamei de mudança de enfoque do gênero para a geração: se nas primeiras décadas do século as reportagens referiam-se, praticamente, apenas a meninas, no final do período, muitos textos enfatizam que os meninos também são vítimas tanto de estupro (legalmente chamado de abuso sexual) quanto de violência intra-familiar. 